\title{
Caffeine affects the biological responses of human hematopoietic cells of myeloid lineage via downregulation of the mTOR pathway and xanthine oxidase activity
}

\author{
Bernhard F. Gibbs ${ }^{1, *}$, Isabel Gonçalves Silva ${ }^{1, *}$, Alexandr Prokhorov ${ }^{1, *}$, Maryam \\ Abooali $^{1}$, Inna M. Yasinska ${ }^{1}$, Maxwell A. Casely-Hayford ${ }^{1}$, Steffen M. Berger ${ }^{2}$, Elizaveta \\ Fasler-Kan' ${ }^{2,3}$, Vadim V. Sumbayev ${ }^{1}$ \\ ${ }^{1}$ School of Pharmacy, University of Kent, Chatham Maritime, ME4 4TB Kent, United Kingdom \\ ${ }^{2}$ Department of Pediatric Surgery and Department of Clinical Research, Inselspital, University Hospital, University of Bern, \\ $\mathrm{CH}-3010$ Bern, Switzerland \\ ${ }^{3}$ Department of Biomedicine, University of Basel and University Hospital Basel, CH-4031 Basel, Switzerland \\ *These authors have contributed equally to this work \\ Correspondence to: \\ Vadim Sumbayev, e-mail: V.Sumbayev@kent.ac.uk \\ Elizaveta Fasler-Kan, e-mail: elizaveta.fasler@insel.ch \\ Keywords: myeloid cells, caffeine, Inflammation, allergy \\ Received: July 06, $2015 \quad$ Accepted: August 31, $2015 \quad$ Published: September 11, 2015
}

\section{ABSTRACT}

Correction of human myeloid cell function is crucial for the prevention of inflammatory and allergic reactions as well as leukaemia progression. Caffeine, a naturally occurring food component, is known to display anti-inflammatory effects which have previously been ascribed largely to its inhibitory actions on phosphodiesterase. However, more recent studies suggest an additional role in affecting the activity of the mammalian target of rapamycin (mTOR), a master regulator of myeloid cell translational pathways, although detailed molecular events underlying its mode of action have not been elucidated. Here, we report the cellular uptake of caffeine, without metabolisation, by healthy and malignant hematopoietic myeloid cells including monocytes, basophils and primary acute myeloid leukaemia mononuclear blasts. Unmodified caffeine downregulated mTOR signalling, which affected glycolysis and the release of pro-inflammatory/pro-angiogenic cytokines as well as other inflammatory mediators. In monocytes, the effects of caffeine were potentiated by its ability to inhibit xanthine oxidase, an enzyme which plays a central role in human purine catabolism by generating uric acid. In basophils, caffeine also increased intracellular cyclic adenosine monophosphate (CAMP) levels which further enhanced its inhibitory action on mTOR. These results demonstrate an important mode of pharmacological action of caffeine with potentially wide-ranging therapeutic impact for treating non-infectious disorders of the human immune system, where it could be applied directly to inflammatory cells.

\section{INTRODUCTION}

Caffeine (1,3,7-trimethylxanthine) is a purine alkaloid present in the leaves, seeds or nuts of a number of plants and is consumed by many people worldwide on a daily basis due to its presence in tea or coffee. In humans, caffeine is rapidly demethylated by cytochrome $\mathrm{P} 450$ isoform 1A2 and then converted mostly into methylated derivatives of uric acid by the enzyme xanthine oxidase (XOD) [1]. For a long time caffeine was recognised as an isosteric inhibitor of cyclic adenosine monophosphate phosphodiesterase (cAMP-PDE) which upregulates intracellular cAMP levels [2]. Caffeine was also found to reduce the role of glycolysis in cell energy metabolism via upregulation of lipid degradation (lipolysis) [3, 4].

Recent evidence demonstrated that human hematopoietic cells do not express the cytochrome P450 1A2 isoform and thus should not be able to metabolise caffeine, resulting in the effects of unmodified caffeine [5]. In this case, caffeine could competitively inhibit 
XOD [6] rather than act as its substrate (most of the other methylxanthines can be converted by XOD). Moreover, several stable purines including caffeine were recently found to inhibit the activity of the mammalian target of rapamycin (mTOR) in somatic cells $[7,8]$. It was also demonstrated that at high concentrations $(5 \mathrm{mM})$, caffeine is capable of inhibiting the mTOR pathway in HOS osteosarcoma cells [7]. In addition, $10 \mathrm{mM}$ caffeine was able to inhibit the PI3K/Akt/mTOR/p70S6K pathway in various cell lines including SH-SY5Y neuroblastoma cells and HeLa cells [9]. $10 \mathrm{mM}$ caffeine was even capable of inhibiting the phosphorylation (Ser473) of Akt in SH-SY5Y cells [9]. In myeloid cells mTOR, a highly conserved serine/ threonine kinase, acts as a central regulator of cell growth and metabolism and plays crucial pathophysiological roles in host immune defence, allergic reactions and leukaemia [10]. Importantly, the mTOR pathway plays a pivotal role in non-hypoxic activation of the hypoxia-inducible factor 1 (HIF-1) transcription complex in human myeloid cells. HIF-1 controls the expression of over 40 target genes responsible for glycolysis, angiogenesis and cell adhesion - physiological processes which form a critical part of myeloid cell function in the human immune system. This transcription complex, containing an inducible $\alpha$ and a constitutive $\beta$ subunit, is a major component of the myeloid cell stress adaptation machinery [11, 12]. Therefore, inhibiting the mTOR/HIF-1 metabolic/signalling axis could be an excellent therapeutic strategy for treating human disorders associated with myeloid cell function - leukaemia, autoimmune disease, and allergy. However, existing mTOR inhibitors are toxic and can cause major side effects and adverse drug reactions. Thus, if the inhibitory activity of caffeine on mTOR has indeed been overlooked for decades, this agent may be an excellent non-toxic drug candidate for the correction of pathophysiological responses of human hematopoietic cells of myeloid lineage.

Here we report for the first time that caffeine inhibits the activation of MTOR in THP-1 human myeloid leukaemia cells, primary human acute myeloid leukaemia (AML) cells and primary human basophils. In THP-1 and primary AML cells caffeine was also found to inhibit XOD. In all cases, the caffeine-mediated attenuation of the mTOR pathway led to the downregulation of ligandinduced glycolysis and cytokine/growth factor/mediator production. Caffeine is known to upregulate lipolysis through activation of hormone sensitive lipase (HSL). This upregulates the Krebs' cycle leading to decreased intracellular levels of 2-oxoglutarate (2-OG), thus preventing degradation of HIF-1 $\alpha$ protein (the inducible HIF-1 subunit) by a classical mechanism controlled by HIF-1 $\alpha$ prolyl hydroxylases (PHDs). This effect was observed in all of the myeloid cell types studied except for basophils, where HIF-1 $\alpha$ accumulation was less PHD-dependent and caffeine completely blocked IgEinduced HIF-1 $\alpha$ accumulation. High performance liquid chromatography (HPLC) experiments demonstrated that caffeine entered all of the above cell types and was not metabolised. Taken together, our results reveal novel mechanisms for the downregulatory effects of caffeine on the biological responses of human myeloid cells.

\section{RESULTS}

\section{Caffeine inhibits ligand-induced activation of the mTOR pathway and its downstream effects in THP-1 human AML cells}

We first investigated the effects of caffeine on ligandinduced mTOR activation through phosphorylation of its S2448 residue in THP-1 cells. Cells were exposed for $4 \mathrm{~h}$ to ligands (see below) with or without $1 \mathrm{~h}$ pre-treatment with $1 \mathrm{mM}$ caffeine (this concentration corresponds to a therapeutic dose of caffeine and is well below the toxic dose [13]). In line with our previous observations [10], we found that pro-inflammatory ligands of Tolllike receptors (TLRs) 2 (plasma membrane-associated TLR $-1 \mu \mathrm{g} / \mathrm{ml}$ peptidoglycan (PGN) was used as a ligand), 7/8 (endosomal TLRs recognising viral single-stranded RNA $-0.1 \mu \mathrm{g} / \mathrm{ml}$ resiquimod (R848) was employed as a ligand) induce activating S2448 phosphorylation of mTOR. The same effect was observed for stem cell factor (SCF), a major hematopoietic factor which is also known to promote growth of leukaemia cells, where caffeine $(1 \mathrm{mM})$ attenuated its effect in all cases (Figure 1). Intriguingly, caffeine alone did not significantly reduce phospho-S2448 mTOR in non-stimulated cells but significantly reduced background levels of phospho-T389 p70 S6K1 and phospho-S65 eIF4E-BP1 (see Figure 1 for details). This suggests that caffeine is likely to act directly on mTOR as well, which would prevent further phosphorylation but not impact on existing activity. The presence of caffeine close to the catalytic site (in the active site of mTOR) would almost certainly affect its kinase activity. However, it is important to stress that phosphorylation of mTOR at the inhibitory T2446 site was not increased by caffeine. This observation clearly suggests that caffeine is unlikely to enhance the activity of this mTOR downregulatory pathway and is likely to be a potential direct mTOR inhibitor, as some other purine containing compounds (such as cAMP) do [8]. Phosphorylation levels of its substrates (indicators of mTOR kinase activity) - p70 S6 kinase 1 (p70 S6K1 - at position T389) and eukaryotic initiation factor 4E-binding protein 1 (eIF4E-BP1 at position S65) were also significantly upregulated by all the employed ligands as well as phosphorylation of S2448 mTOR. All these processes were attenuated by caffeine (Figure 1).

We next investigated the effects of caffeine on mTOR downstream and associated biochemical pathways induced by PGN, R848 and SCF. We found that caffeine did not downregulate PGN-induced accumulation of HIF-1 $\alpha$ protein. This was in line with a significant decrease in HIF-1 $\alpha$ PHD activity in cells treated with PGN 

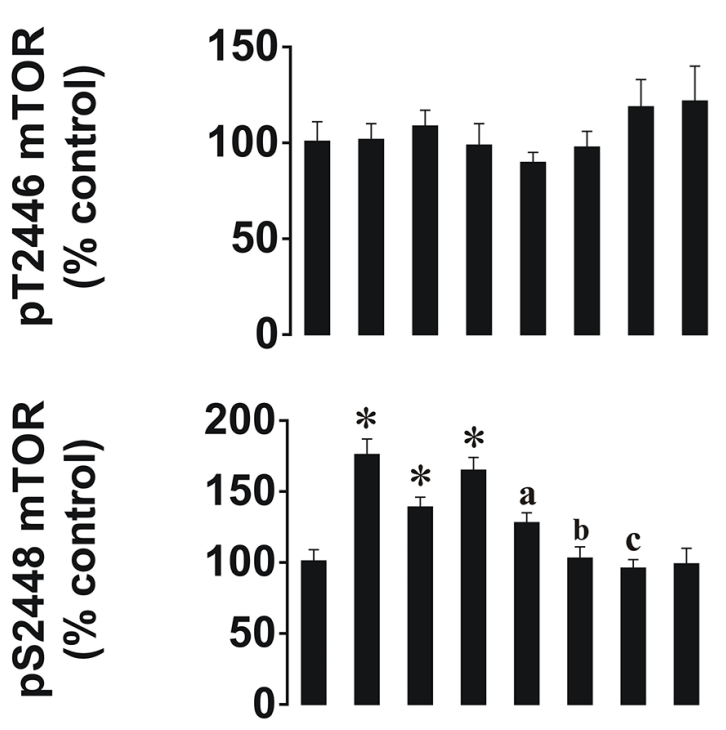

ELISA
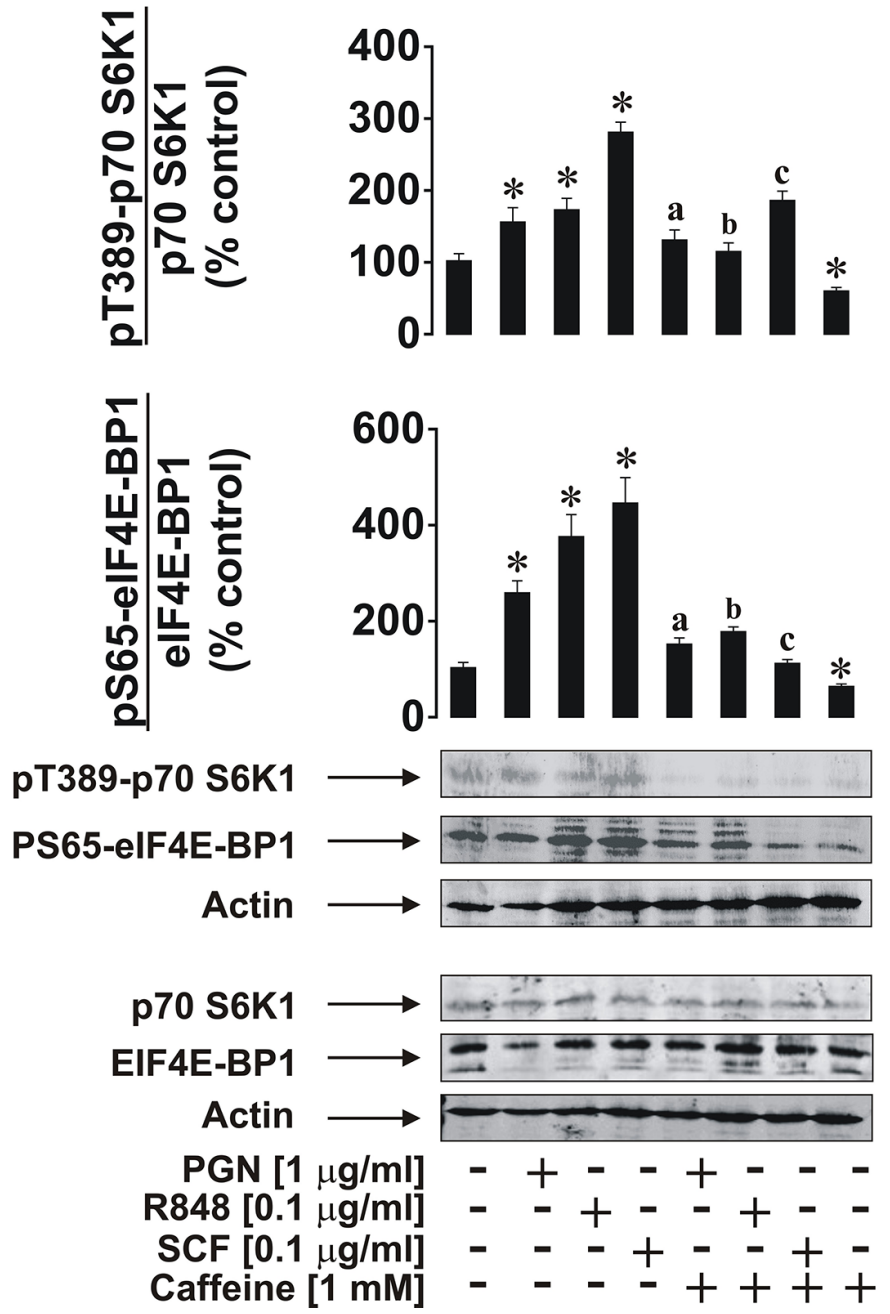

Figure 1: Caffeine inhibits the ligand-induced mTOR signalling pathway in THP-1 human acute myeloid leukaemia cells. Cells were exposed for $4 \mathrm{~h}$ to the indicated concentrations of PGN, R848 or SCF with or without $1 \mathrm{~h}$ pre-treatment with $1 \mathrm{mM}$ caffeine. Levels of pS2448 and pT2446 phospho-mTOR as well as phosphorylation of its downstream enzymes were analysed as outlined in the Materials and Methods. Western blot data show one representative experiment of four that gave similar results and were quantitatively analysed. Quantitative data are shown as means \pm S.D; ${ }^{*}-p<0.01$ vs. control $(n=4), \mathrm{a}-p<0.01$ vs. PGN alone, $\mathrm{b}-p<0.01$ vs. R848 alone and $\mathrm{c}-p<0.01 \mathrm{vs}$. SCF alone. 
in the presence of caffeine (Figure 2A). ATP levels, which are often controlled in a HIF-1-dependent manner, were decreased in cells co-stimulated with PGN and caffeine. Levels of cAMP did not undergo significant changes, probably owing to the fact that receptors involved in these events are not G-protein-coupled [14]. They do not provoke adenylate cyclase activation/cAMP production and thus cAMP-PDE-inhibiting activity of caffeine has no effect in this case. AMP levels were also not increased by PGN stimulation, which conforms with our previous observations (Figure 2B). The presence of caffeine did not increase AMP levels despite a significant decrease in PGN-induced XOD activity (Figure 2C). This is likely to be caused by the inhibition of hypoxanthine-guanine phosphoribosyl transferase (HGPRT), an enzyme which converts hypoxanthine (accumulated when XOD was inhibited) into inosine monophosphate (IMP), which is then converted into AMP $[15,16]$. However, we could not rule out the possibility of caffeine-dependent effects on other enzymes involved in the conversion of hypoxanthine into AMP. Intracellular reactive oxygen species (ROS) levels upregulated by PGN were also unaffected by caffeine, possibly because XOD is not the main contributor to the intracellular ROS pool (NADPH oxidase plays this role [17]) in this case (Figure 2C). Glycolysis, which was significantly upregulated by PGN, was reduced to its basic level (Figure 2D). This is not surprising, since translation of glycolytic enzymes is likely to be an mTOR-dependent process in human hematopoietic cells [18]. However, intracellular 2-OG levels were almost completely abolished by caffeine (Figure 2D). This may be due to the caffeine-dependent upregulation of lipolysis and, therefore, the Krebs' cycle (which would lead to a reduction of intracellular 2-OG levels and a subsequent decrease in 2-OG-dependent HIF-1 $\alpha$ PHD activity, where 2-OG is used as a cofactor [19]; which we observed (Figure 2A)). Furthermore, the pro-inflammatory responses of THP-1 cells induced by PGN (release of TNF- $\alpha$ and IL-6) were attenuated by caffeine (Figure 2E).

The situation with endosomal TLRs 7 and 8 was slightly different, where THP-1 cells were exposed to $0.1 \mu \mathrm{g} / \mathrm{ml} \mathrm{R} 848$ with or without $1 \mathrm{~h}$ pre-treatment with $1 \mathrm{mM}$ caffeine. We found that, unlike with PGN, R848induced HIF-1 $\alpha$ accumulation was significantly reduced by caffeine. HIF-1 $\alpha$ PHD activity was significantly decreased by R848 (as we have reported before [20]), but in the presence of caffeine, PHD activity did not reduce further and was even slightly elevated compared to exposure to R848 alone (Figure 3A). ATP, AMP and cAMP levels in the cells were not affected by caffeine as in the experiments with PGN (Figure 3B). Caffeine inhibited R848-induced XOD activity but also (unlike following the exposure of THP-1 cells to PGN) it reduced intracellular ROS levels upregulated by R848. In the case of endosomal TLRs, XOD contributes to the intracellular
ROS pool [17] together with NADPH oxidase (Figure 3C). This result explains the caffeine-dependent decrease in HIF-1 $\alpha$ accumulation in THP-1 cells induced by R848, since ROS may play a primary role in the process. Glycolysis was also significantly upregulated in the presence of R848 and this effect was slightly reduced by caffeine. 2-OG levels were significantly reduced (by ca. $50 \%$ ) by caffeine (Figure 3D). R848-induced production of IL- 6 and TNF- $\alpha$ were significantly lower in the presence of caffeine (Figure 3E).

SCF-induced biological responses of THP-1 cells were also affected in a way similar to that observed for PGN (see above). THP-1 cells were exposed for 4 $\mathrm{h}$ to $0.1 \mu \mathrm{g} / \mathrm{ml} \mathrm{SCF}$ with or without $1 \mathrm{~h}$ pre-treatment with $1 \mathrm{mM}$ caffeine. We found that SCF-induced HIF$1 \alpha$ accumulation was not decreased in the presence of caffeine which corresponded to a striking decrease in HIF-1 $\alpha$ PHD activity in the cells (Figure 4A). ATP, cAMP and AMP levels were not affected at all (Figure 4B). As with TLRs, the Kit receptor, which recognises SCF as a ligand, is not a G-protein coupled receptor (it is a typical receptor tyrosine kinase), and therefore no changes in cAMP levels were observed. SCF-induced XOD activity was reduced by caffeine, however intracellular ROS levels were slightly upregulated by SCF and remained unchanged in the presence of caffeine (Figure 4C). SCF also upregulated glycolysis and caffeine attenuated this process as well as significantly reduced intracellular 2-OG levels (Figure 4D). Finally, SCF-induced vascular endothelial growth factor (VEGF) production was significantly increased upon exposure of the cells to SCF, but this process was attenuated by caffeine (Figure 4D).

In order to confirm that caffeine is able to directly inhibit XOD and, if so, to characterise this process, we studied the kinetics of caffeine effects on purified bovine liver XOD activity using the Lineweaver-Burk approach [21]. We found that caffeine isosterically (in a competitive manner) inhibited XOD (Figure 5). However, the $\mathrm{Ki}$ was only $4.022 \mathrm{mM}$ suggesting that caffeine is a weak inhibitor compared to classic XOD inhibitors (for example, allopurinol and sodium tungstate). This confirmed our previous studies showing the ability of caffeine to inhibit XOD in vitro but not in vivo due to demethylation of the drug.

\section{Caffeine affects SCF-induced responses of primary human AML cells in an mTOR- dependent manner}

We sought confirmation of our results using primary human leukocytes. For this purpose we used primary acute myeloid leukaemia cells AML-PB001F purchased from AllCells (Alameda, CA, USA). Cells were exposed to $0.1 \mu \mathrm{g} / \mathrm{ml} \mathrm{SCF}$ (these cells express high levels of the Kit receptor) for $4 \mathrm{~h}$ with or without $1 \mathrm{~h}$ pre-treatment with $1 \mathrm{mM}$ caffeine. We found that SCF induced a significant 

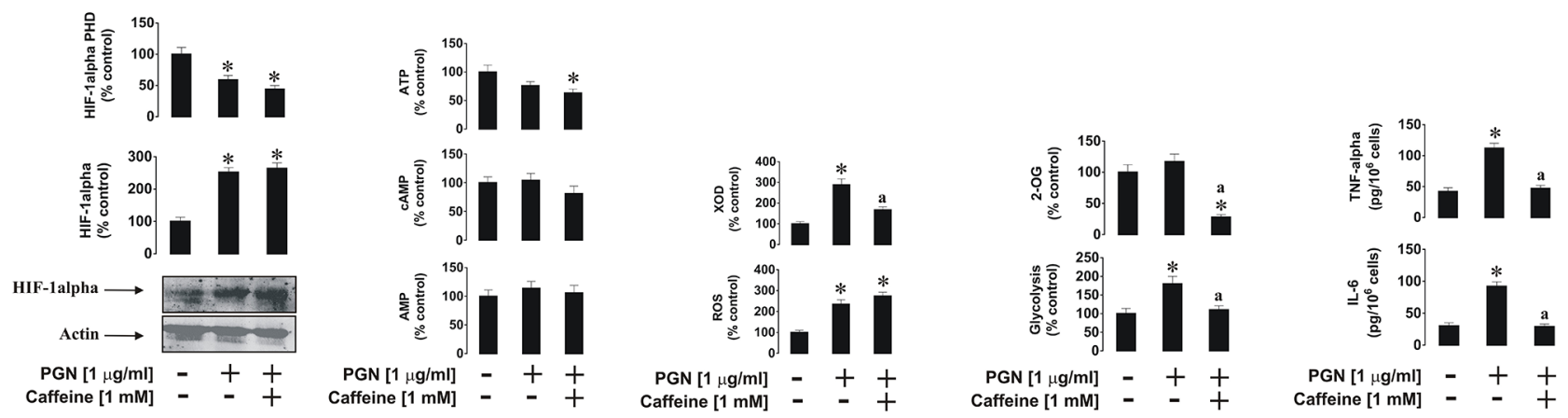

Figure 2: Effects of caffeine on TLR2-mediated biological responses of THP-1 cells. Cells were exposed for 4 h to PGN with or without $1 \mathrm{~h}$ pre-treatment with $1 \mathrm{mM}$ caffeine before assessing the indicated biological responses: A. HIF-1 $\alpha$ accumulation, B. ATP/ cAMP/AMP levels, C. XOD activity and intracellular ROS pool, D. glycolysis and 2-OG level as well as E. TNF- $\alpha / \mathrm{IL}-6$ release. Western blot data show one representative experiment of three that gave similar results. Quantitative data are shown as means \pm S.D; * $-p<0.01$ vs. control $(n=3), \mathrm{a}-p<0.01$ vs. PGN alone.

A

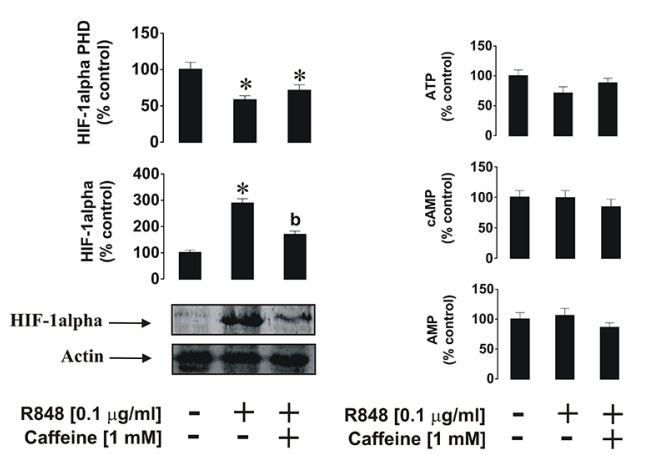

C

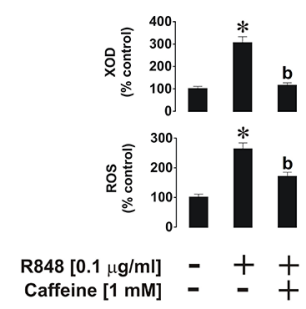

D

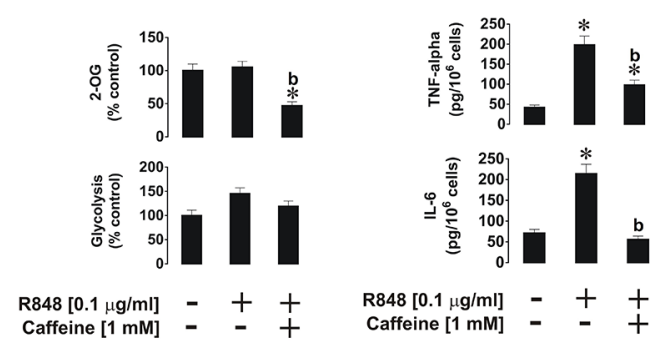

Figure 3: Effects of caffeine on TLR7/8-mediated biological responses of THP-1 cells. Cells were exposed for $4 \mathrm{~h}$ to R848 with or without $1 \mathrm{~h}$ pre-treatment with $1 \mathrm{mM}$ caffeine before analysing A. HIF-1 $\alpha$ accumulation, B. ATP/cAMP/AMP levels, C. XOD activity and intracellular ROS pool, D. glycolysis and 2-OG level as well as E. TNF- $\alpha /$ IL-6 release. Western blot data show one representative experiment of three that gave similar results. Quantitative data are shown as means \pm S.D; ${ }^{*}-p<0.01$ vs. control $(n=3)$, $\mathrm{b}-p<0.01$ vs. R848 alone.

A
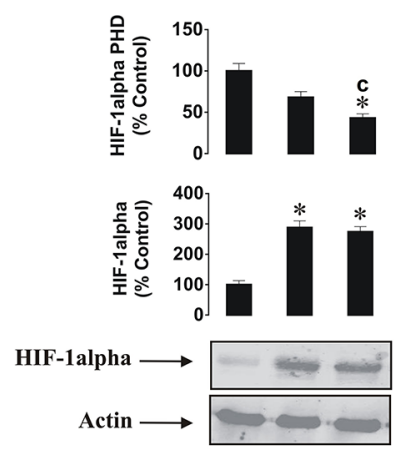

$\begin{array}{llll}\operatorname{SCF}[0.1 \mu \mathrm{g} / \mathrm{ml}] & = & + & + \\ \text { Caffeine }[1 \mathrm{mM}] & - & - & +\end{array}$
B
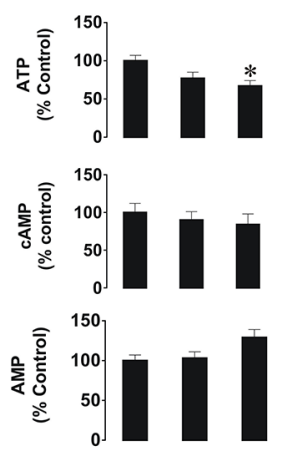

$\mathrm{SCF}[0.1 \mu \mathrm{g} / \mathrm{ml}]=++$
Caffeine $[1 \mathrm{mM}]=-+$
C
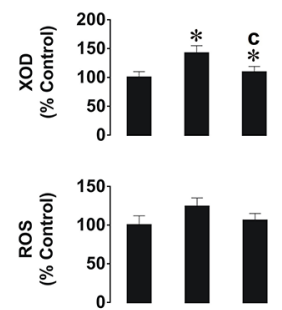

$\mathrm{SCF}[0.1 \mu \mathrm{g} / \mathrm{ml}]$
Caffeine $[1 \mathrm{mM}]=++$
D
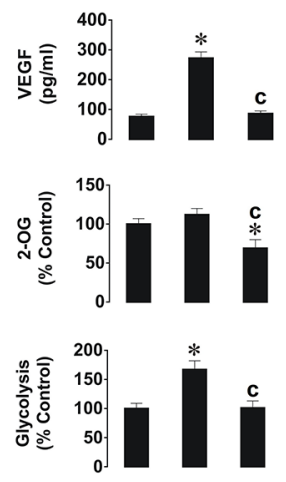

SCF $[0.1 \mu \mathrm{g} / \mathrm{ml}] \quad-\quad+$ Caffeine $[1 \mathrm{mM}]=-$

Figure 4: Effects of caffeine on SCF-induced Kit receptor activation in- THP-1 cells. Cells were exposed for $4 \mathrm{~h}$ to $\mathrm{SCF}$ with or without $1 \mathrm{~h}$ pre-treatment with $1 \mathrm{mM}$ caffeine before analysing A. HIF-1 $\alpha$ accumulation, B. ATP/cAMP/AMP levels, C. XOD activity and intracellular ROS pool, D. glycolysis and 2-OG level as well as VEGF release. Western blot data show one representative experiment of three that gave similar results. Quantitative data are shown as means $\pm \mathrm{S} . \mathrm{D} ;{ }^{*}-p<0.01 \mathrm{vs}$. control $(n=3)$, c $-p<0.01$ vs. SCF alone. 


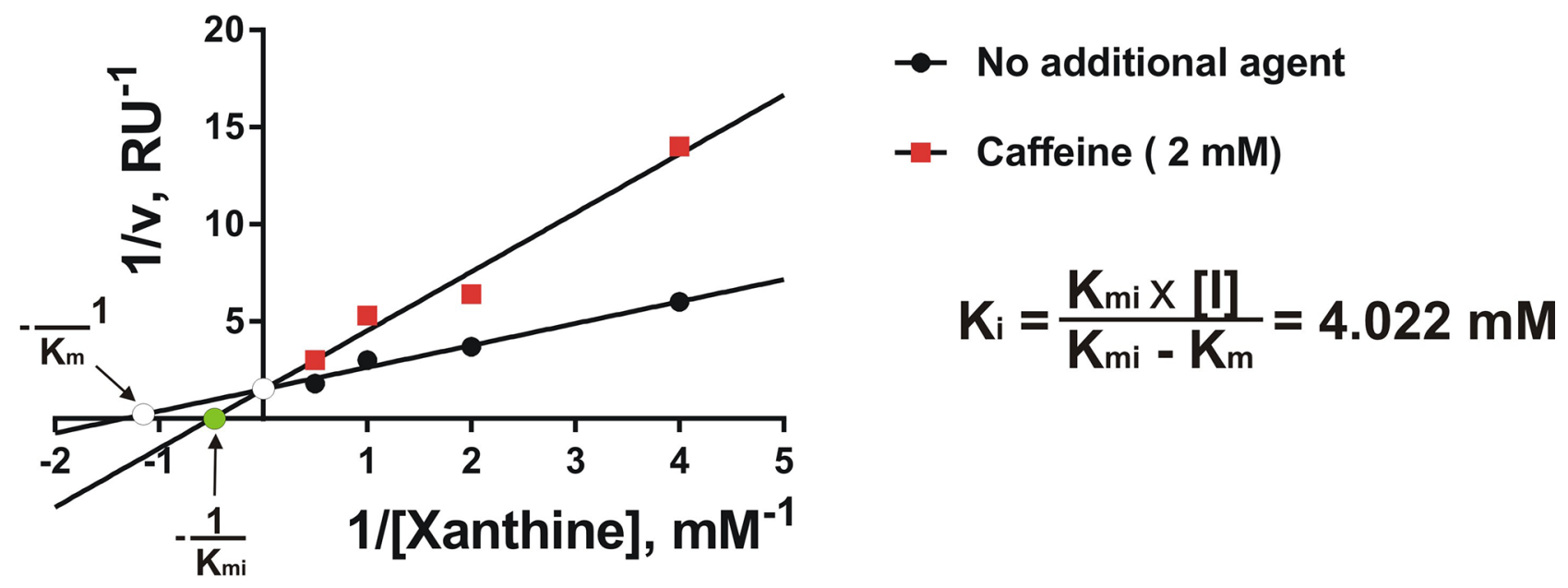

Figure 5: Caffeine is a weak competitive inhibitor of XOD. Kinetics of the effects of caffeine on the activity of purified bovine liver XOD were analysed as described in the Materials and methods. Each point was analysed in quadruplicate.

increase in mTOR phosphorylation at position S2448 and respectively phosphorylation of its substrates - p70 S6K1 and eIF4E-BP1 (Figure 6A). These levels were compared with those in resting primary human leukocytes (PL) obtained from healthy donors (Figure 6A). As in THP-1 cells, SCF induced significant upregulation of HIF-1 $\alpha$ accumulation, glycolysis, VEGF release and XOD activity. All these effects were attenuated by caffeine (in the case of HIF-1 $\alpha$ - downregulated; the level was still significantly higher than the control) (Figure 6B). Interestingly, background levels of HIF-1 $\alpha$, pS2448 mTOR and XOD activity were significantly higher in primary AML cells compared to primary "healthy" leukocytes (PL) suggesting that these factors/pathways are crucial for AML cell function. Importantly, resting primary human leukocytes obtained from the blood of healthy donors did not accumulate detectable amounts of HIF-1 $\alpha$ protein.

Given the effects of caffeine on AML cell function, we next determined the concentrationdependent actions of caffeine on these cells following exposure to $0.1 \mu \mathrm{g} / \mathrm{ml} \mathrm{SCF}$ for $4 \mathrm{~h}$ with or without $1 \mathrm{~h}$ pre-treatment with $0.01,0.1$ and $1 \mathrm{mM}$ caffeine. Levels of pS2448 mTOR were monitored as a biochemical response. We found that SCF-dependent mTOR phosphorylation was significantly affected by 1 and 0.1 but not $0.01 \mathrm{mM}$ caffeine (Figure 7).

\section{Caffeine downregulates anti-IgE-induced activation of human basophils by affecting mTOR signalling}

We were next interested in investigating the effects of caffeine on primary human basophils. These terminally differentiated granulocytes display biochemically similar but pathophysiologically different responses compared to THP-1 and primary AML cells. Furthermore, basophils play a crucial role in human allergic reactions since they readily respond to IgE-dependent triggering, although compared to leukaemic myeloid cells they are relatively unresponsive to SCF [22] and TLR2/4 ligands [23]. Stimulation of primary human basophils with $1 \mu \mathrm{g} / \mathrm{ml}$ anti-IgE led to the activation of mTOR phosphorylation at S2448, which was attenuated by caffeine (Figure 8). Similar effects were observed regarding the phosphorylation of mTOR substrates (Figure 8).

As shown previously [24], HIF-1 $\alpha$ accumulation was upregulated by anti-IgE. This process was completely blocked by caffeine and the process appeared to be independent of PHD activity, since no significant changes were observed in enzyme activity (Figure 9A). Importantly, we could not detect any XOD activity in basophils, which is supported by our previous observations [21]. Western blot analysis (Figure 9A) demonstrated the absence of XOD protein in basophils. ATP and AMP levels were not affected by any of the treatments; however, cAMP levels were significantly upregulated by anti-IgE and were further increased in the presence of $1 \mathrm{mM}$ caffeine (Figure 9B). This suggests that IgE-induced responses in basophils are indirectly linked to G-protein-coupled receptor signalling, possibly due to the actions of histamine acting through $\mathrm{H} 2$ receptors, which may serve as a negative feedback loop limiting further basophil degranulation and histamine release. Intracellular ROS levels were not affected which confirms our previous findings suggesting that IgE-induced basophil responses are orchestrated in a redox-independent manner (Figure 9C). IgE-dependent histamine release was significantly affected by caffeine which is in line with the observed caffeine-dependent downregulation of IgE-induced glycolysis and 2-OG levels (Figure 9D). However, the effect associated with 2-OG levels did not impact HIF-1 $\alpha$ accumulation or PHD activity, further confirming our hypothesis that this process is most likely to be PHD-independent in basophils. 
A
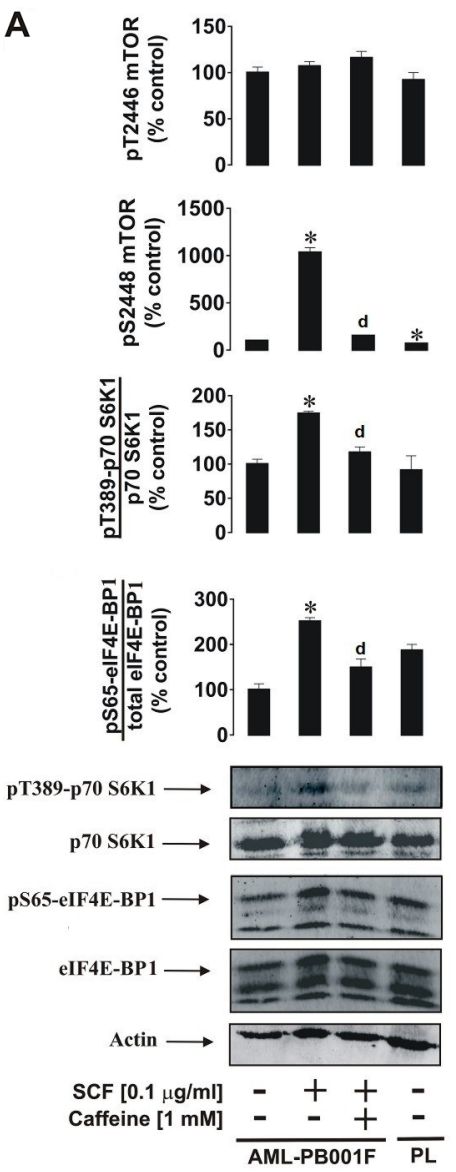

B
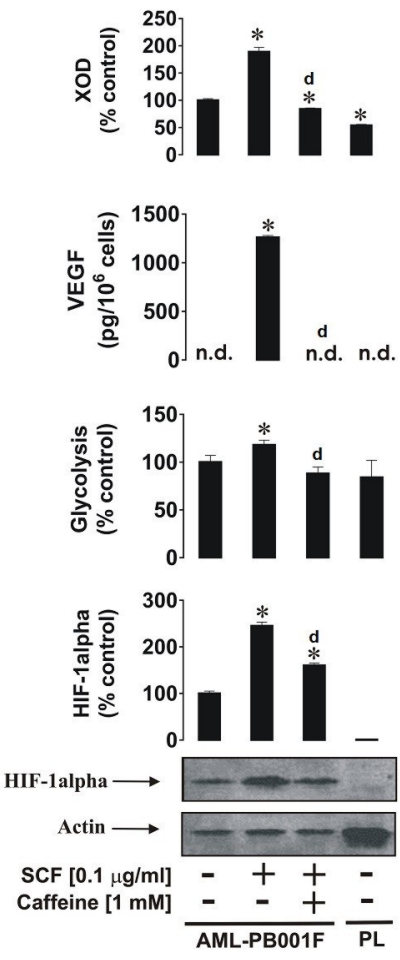

Figure 6: Effects of caffeine on SCF-induced Kit receptor activation in primary human AML cells. AML-PB001F cells were exposed for $4 \mathrm{~h}$ to SCF with or without $1 \mathrm{~h}$ pre-treatment with $1 \mathrm{mM}$ caffeine before analysis of A. mTOR phosphorylation and its biological activity and B. HIF- $1 \alpha$ accumulation, glycolysis, VEGF release and XOD activity. Western blot data $(50,000$ cells per well were loaded in each case for AML cells and 90,000 for healthy primary leucocytes) show one representative experiment of three-four (using cells derived from different donors) that gave similar results. In both panels A and B we also show the results obtained from non-treated healthy primary human leukocytes (PL) handled as described in Materials and Methods. Quantitative data are shown as means \pm S.D; * $-p<0.01$ vs. control ( $n=4$ for panel A and $n=3$ for panel $\mathrm{B}), \mathrm{d}-p<0.01$ vs. SCF alone.

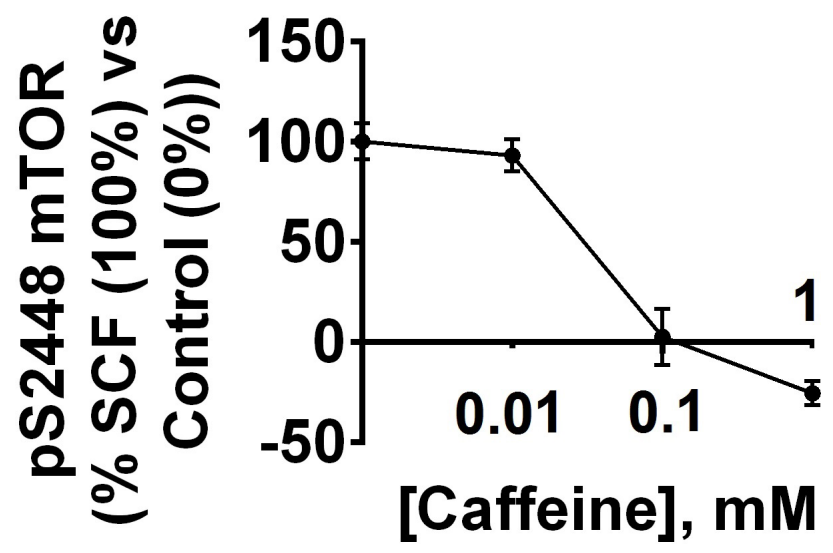

Figure 7: Dose-dependent effects of caffeine on SCF-induced Kit receptor-mediated intracellular pS2448 mTOR levels. AML-PB001F cells were exposed for $4 \mathrm{~h}$ to $0.1 \mu \mathrm{g} / \mathrm{ml}$ of SCF with or without $1 \mathrm{~h}$ pre-treatment with $0.01,0.1$ or $1 \mathrm{mM}$ caffeine. pS2448 mTOR levels were analysed. Quantitative data are shown as means \pm S.D of three individual experiments; ${ }^{*}-p<0.01$ vs. control. 


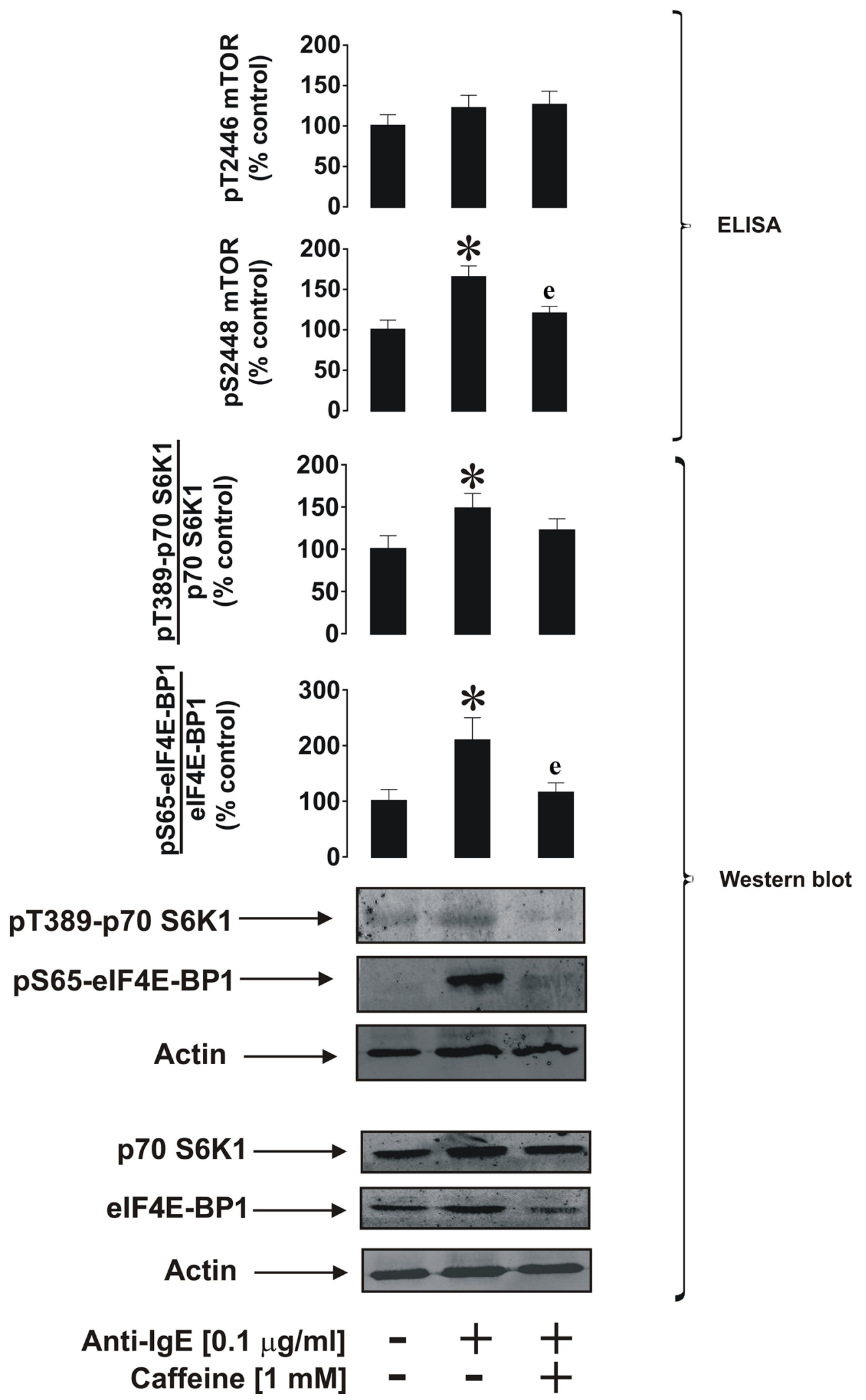

Figure 8: Caffeine inhibits ligand-induced mTOR signalling pathway in primary human basophils. Cells were exposed for $2 \mathrm{~h}$ to $0.1 \mu \mathrm{g} / \mathrm{ml}$ anti-IgE with or without 30 min pre-treatment with $1 \mathrm{mM}$ caffeine. pS2448 and pT2446 phospho-mTOR levels as well as phosphorylation of its downstream enzymes were analysed as described in Materials and Methods. Western blot data show one representative experiment of four that gave similar results. Quantitative data are shown as means $\pm \mathrm{S} . \mathrm{D} ;{ }^{*}-p<0.01 \mathrm{vs}$. control $(n=4), \mathrm{e}-p<0.01 \mathrm{vs.}$ anti-IgE alone. 


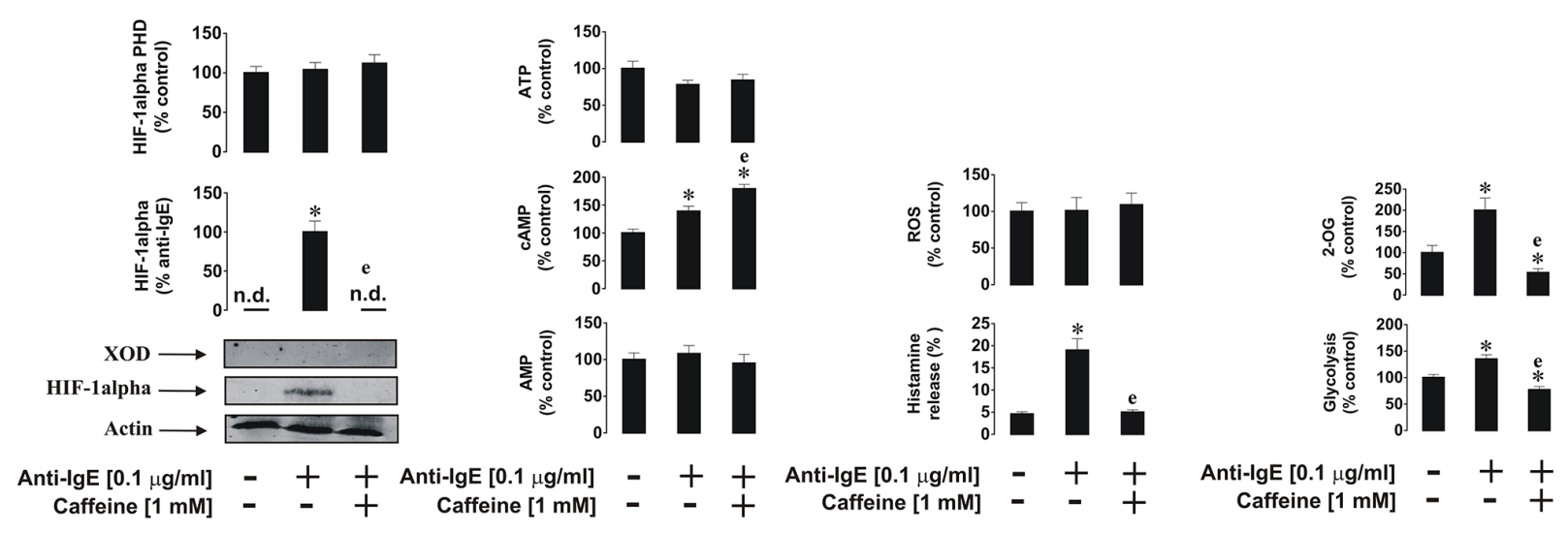

Figure 9: Effects of caffeine on the anti-IgE-induced biological responses of primary human basophils. Cells were exposed for $2 \mathrm{~h}$ to $0.1 \mu \mathrm{g} / \mathrm{ml}$ anti-IgE with or without $30 \mathrm{~min}$ pre-treatment with $1 \mathrm{mM}$ caffeine before analysis of A. HIF-1 $\alpha$ accumulation and XOD protein levels, B. ATP/cAMP/AMP levels, C. intracellular ROS pool and histamine release, D. glycolysis and 2-OG level. Western blot data show one representative experiment of three that gave similar results. Quantitative data are shown as means \pm S.D ; $*-p$ $<0.01$ vs. control $(n=3), \mathrm{e}-p<0.01$ vs. anti-IgE alone.

We next further verified the differential involvement of XOD in the biological responses of myeloid cells by assessing whether basophil function could be affected by XOD inhibitors/substrate. We studied the effects of the XOD inhibitor allopurinol, the XOD substrate hypoxanthine (hypoxanthine - chemically is an allopurinol isomer) and the highly specific XOD inhibitor sodium tungstate. Neither of these compounds, however, was able to significantly affect anti-IgE-stimulated basophil histamine release and HIF- $1 \alpha$ accumulation (Supplementary Figure S1). We also noticed that, while $0.01 \mathrm{mM}$ caffeine did not significantly inhibit IgEinduced histamine release, HIF-1 $\alpha$ accumulation was still markedly reduced at this low caffeine concentration (Supplementary Figure S1). This provides further confirmation of our previous observations [24] suggesting that histamine release and HIF-1 activation are controlled by biochemically independent pathways.

\section{Caffeine is taken up but not metabolised by human myeloid cells}

In order to ascertain whether the observed effects described above were due to caffeine or a metabolite we investigated whether the different myeloid cell types employed in the study could metabolised caffeine following cellular uptake. We found that neither THP-1 cells nor primary human leukocytes nor basophils contained the cytochrome P450 1A2 isoform which is primarily responsible for caffeine demethylation (data not shown since they are at zero levels). We then assessed whether caffeine (a) enters the studied cells and (b) is metabolised through other pathways. For this purpose we used high-performance liquid chromatography (HPLC) in order to detect caffeine and its metabolites. As a positive control we used urine of healthy volunteers following consumption of caffeine by them. In the urine we detected six caffeine metabolites as well as unmodified caffeine, suggesting that all the metabolites are detectable by our method and that caffeine is mostly metabolised in vivo in humans (Figure 10). In both THP-1 cells and primary human basophils we detected caffeine but none of its metabolites, suggesting that caffeine is endocytosed into these myeloid cells but is not further metabolised. This finding was confirmed by the fact that none of the caffeine metabolites was detected in the culture medium; only unmodified caffeine was detected (Figure 10). These data suggest that the effects of caffeine observed in the study were solely caused by unmodified caffeine.

Taken together, our results demonstrate for the first time that caffeine affects the biological responses of human myeloid cells, including leukaemia cell lines, primary AML cells and primary human basophils by downregulating the mTOR pathway and differentially inhibiting XOD.

\section{DISCUSSION}

Caffeine, a plant-derived purine alkaloid, was chemically identified over 100 years ago and its effects were observed even before Biochemistry developed into an independent field of science [1]. However, due to its metabolism and labile properties, the effects of caffeine in human hematopoietic cells (where it remains unmetabolised) were completely overlooked. Given the fact that some purine compounds were found to directly inhibit mTOR, we were interested to see whether caffeine displays such an activity too. Alternatively, unmodified caffeine was found to inhibit XOD, which we recently showed to play a major role in myeloid cell responses. We were therefore interested in discovering whether caffeine plays a major role 

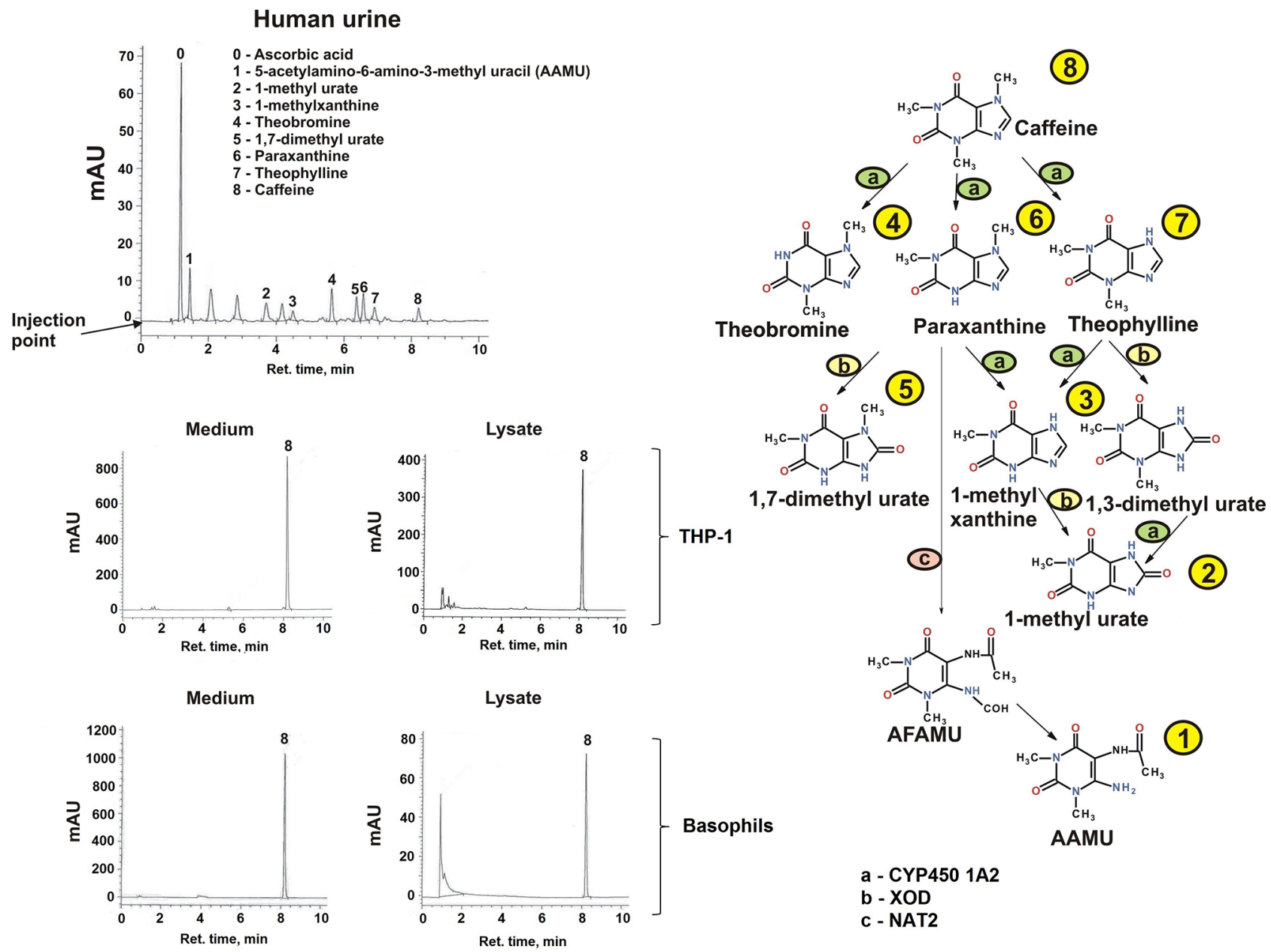

THP-1
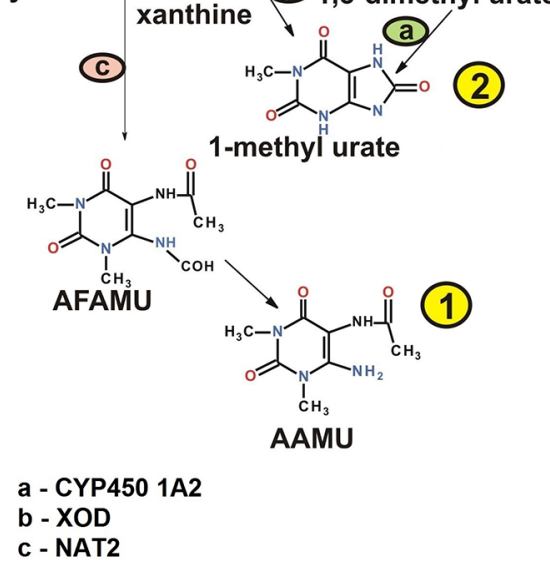

Figure 10: Determination of caffeine and its metabolites in human urine and myeloid cells. Caffeine and its metabolites in human urine (coffee drinkers) and medium/lysates of THP-1 cells (exposed for $4 \mathrm{~h}$ to $1 \mathrm{mM}$ caffeine) and human basophils (exposed for $2 \mathrm{~h}$ to $1 \mathrm{mM}$ caffeine) were detected by HPLC. The caffeine metabolic pathway in humans is also presented indicating how each metabolite is obtained biochemically. CYP4501A - cytochrome P450 A2; XOD - xanthine oxidase; NAT2 - N-acetyltransferase 2; AAMU - 5 Acetylamino-6-amino-3-methyluracil; AFMU - 5 Acetylamino-6-formylamino-3-methyluracil.

in the biological responses of human hematopoietic cells of myeloid lineage based on its potential actions on XOD and mTOR. These leukocytes determine human innate immune responses and are affected during severe human disorders such as AML and allergy. Thus, elucidating a potentially overlooked mechanism of caffeine may result in additional therapeutic uses for this methylxanthine which was rapidly taken up by these myeloid cells but not metabolised.

We analysed the effects of caffeine on the proinflammatory and pro-leukaemic responses of human AML cells using THP- 1 cell line and primary AML cells as well as on the pro-allergic reactions of primary human basophils. Caffeine was found to downregulate activating phosphorylation (S2448 position) of the mTOR protein thus affecting its kinase activity. This occurred in both THP-1 cells (upon exposure to PGN, R848 and SCF) as well as in primary AML cells stimulated with SCF (TLR expression levels are quite low in these cells). Importantly, caffeine did not increase phosphorylation of the T2446 residue of mTOR.
This shows that caffeine does not activate specific mTOR downregulatory cascades, for example the AMPK pathway [10]. Intracellular AMP (specific AMP kinase activator) levels were also not affected by caffeine. However, caffeine inhibited XOD activity in both THP-1 and primary AML cells. Our previous studies showed that inhibition of XOD by allopurinol or sodium tungstate led to a significant increase in intracellular AMP levels and therefore induced AMPKdependent downregulatory phosphorylation of mTOR at position T2446 [21]. Here, we also observed inhibition of XOD but without increases in intracellular AMP levels. Recently, it was reported that caffeine is capable of inhibiting Akt phosphorylation thus preventing mTOR activation (presumably through phosphorylation of its S2448 residue). However, other studies demonstrated that, in tissues expressing high levels of XOD (for example skeletal muscles), high concentrations of caffeine $(10 \mathrm{mM})$ activate AMPK [7]. These tissues, however, can metabolise caffeine. XOD expression in leukocytes (even in AML cells) 
is relatively low compared to other tissues and in basophils where the presence of XOD was even undetectable [21].

Although caffeine is a weak inhibitor of XOD compared to allopurinol and especially sodium tungstate, it might affect the re-use of purines in myeloid cells (this system is quite robust in leukocytes and is not affected by allopurinol or tungastates, which are specific XOD inhibitors only especially tungstates, where tungsten replaces molybdenum in the catalytic site of the enzyme causing its irreversible inhibition). Caffeine is known to inhibit HGPRT, however, in myeloid cells its inhibitory effects are more striking since it is not metabolised in these cells [25]. This means that, upon inhibition of XOD by caffeine, levels of hypoxanthine are increased. However, hypoxanthine can't be converted into IMP and further down to AMP [21] (for more details, see Supplementary Figure S2). This lack of increase in AMP levels prevents the activation of AMP kinase and subsequent phosphorylation of mTOR at T2446.

Inhibition of mTOR and XOD by caffeine did not lead to the attenuation of HIF- $1 \alpha$ accumulation in THP-1 and primary AML cells. This was due to a significant decrease in HIF-1 $\alpha$ PHD activity (resulting from the decrease in intracellular 2-OG levels required for this reaction in form of a co-factor). Caffeine activates lipolysis by upregulating the activity of hormone-sensitive lipase (HSL), which is well expressed in myeloid cells $[4,25]$. This leads to a decrease in glycolysis, which is further supported by a decrease in mTOR kinase activity which is required for translation of glycolytic enzymes $[18,26]$. Such an effect results in the upregulation of the Krebs' cycle and thus in a decrease in intracellular 2-OG levels that affect HIF- $1 \alpha$ PHD activity, thus preventing physiological degradation of HIF- $1 \alpha$ protein. The effects described above are summarised in the scheme presented in the Figure 11.

Caffeine was revealed to inhibit mTOR, thus downregulating glycolysis. Previous reports suggested a possible influence of caffeine on NF-kB activity and calcium-dependent signalling [7, 27]. All these effects are likely to be responsible for the decreases in cytokine production observed in the present study (e.g. TNF- $\alpha$ and IL-6 in the case of TLR ligand stimulation and VEGF when the cells were exposed to SCF). These effects took place in both THP-1 and primary AML cells.

Despite the well-known fact that caffeine is an effective inhibitor of cAMP-PDE [2], no significant changes in intracellular cAMP levels were observed in THP-1 or AML cells. This could be explained by the fact that neither TLRs nor the SCF receptor (Kit) are G-protein coupled receptors. Therefore, they do not activate adenylate cyclase, the enzyme, which converts ATP into cAMP.

A different picture was observed in primary human basophils which did not express detectable amounts of XOD. Here, we also observed inhibition of IgE-induced mTOR kinase activity and abrogation of the mediator (histamine) release. However, HIF-1 $\alpha$ accumulation did not seem to be PHD dependent in these cells and therefore, upon inhibition of mTOR kinase activity, IgE-induced HIF- $1 \alpha$ accumulation was attenuated by caffeine. However, in contrast to AML and THP-1 cells, we observed a significant increase in intracellular cAMP levels in basophils which were further upregulated by caffeine. Basophils release histamine and also express H2-type histamine receptors which are G-protein-coupled and thus activate adenylate cyclase [15]. The cAMP levels induced by the autocrine actions of histamine are therefore preserved by caffeine as an inhibitor of cAMP-PDE. In this case, it is likely that we observed additional inhibition of mTOR activation due to the indirect actions of caffeine by increasing cAMP. All the effects reported were studied at $1 \mathrm{mM}$ caffeine. However, dose-response investigations demonstrated that it displays its activities in primary AML cells and basophils at $0.1 \mathrm{mM}$ though not at $0.01 \mathrm{mM}$.

Taken together, our results demonstrate, for the first time, that unmodified caffeine inhibits mTOR function by targeting its kinase activity during the biological responses of various human myeloid cells. These findings support observations made by other groups regarding caffeine effects on the mTOR pathway in non-blood cells [7, 8]. Furthermore, caffeine inhibits XOD activity but, unlike XOD-specific inhibitors, it does not upregulate the re-use of purines in AML cells. In contrast, basophils do not express detectable amounts of XOD. Since caffeine is a non-toxic drug with relatively few side effects at therapeutic concentrations, and easily metabolised in non-blood cells, our findings may lead to new avenues for therapy of human disorders affecting myeloid hematopoietic cells. However, it is obvious that high concentrations of caffeine would need to be maintained in order to achieve either its anti-inflammatory/anti-allergic effects or to affect SCF-induced biological responses. Because of this, the therapeutic actions of caffeine would more likely be achieved following external applications of this drug. For example, caffeine could be applied as a cream supplement or through other forms of direct application of unmodified caffeine on target myeloid cells with the purpose of their inactivation or elimination (previous studies have shown the ability of caffeine to induce programmed cell death $[7,8])$. Alternatively, for internal applications, one might consider the recently discovered advantages of Nanobiotechnology or other highly specific forms of drug delivery in order to supply caffeine directly to myeloid cells.

\section{MATERIALS AND METHODS}

\section{Materials}

RPMI-1640 medium, foetal calf serum and supplements, caffeine, bovine liver XOD, PGN, goat antihuman-IgE, caffeine metabolites and an ATP luminometric detection kit were purchased from Sigma (Suffolk, UK). AMP/cAMP detection kits were purchased from Promega (Southampton, UK). Maxisorp ${ }^{\mathrm{TM}}$ microtitre plates were obtained from Nunc (Roskilde, Denmark) as well as from 


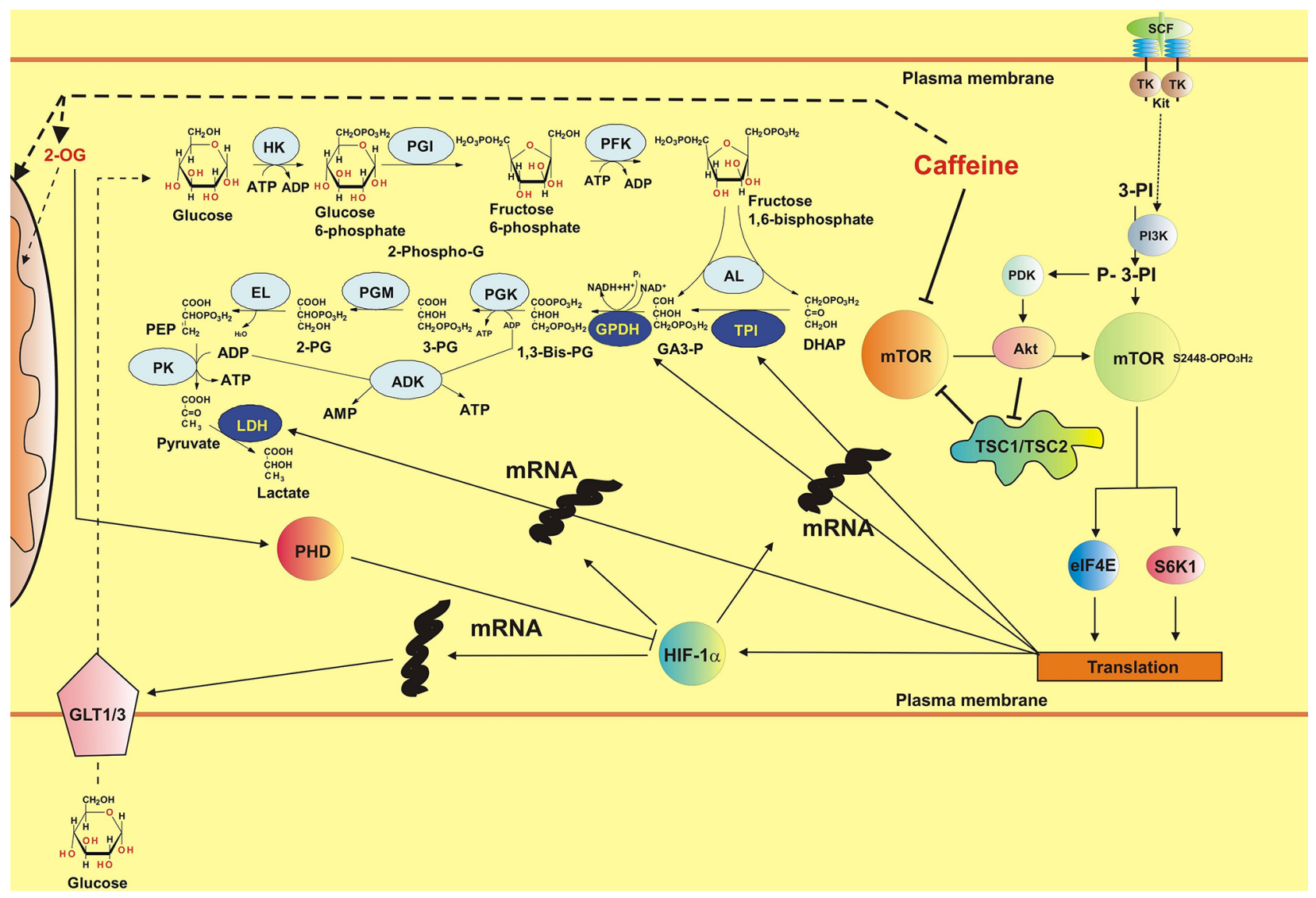

Figure 11: Possible biochemical mechanisms of the effects of caffeine on the mTOR pathway, HIF-1 activity and energy metabolism in human myeloid cells (SCF-induced responses are used as the example). Additional abbreviations used: HK - hexokinase, PGI - phosphoglucose isomerase, PFK - phosphofructokinase, AL - Aldolase, TPI - Triose-phosphate isomerase, GPDH - glyceraldehyde-3-phosphate dehydrogenase, PGK - phosphoglycerate kinase, PGM - phosphoglycerate mutase, EL - enolase, PK - pyruvate kinase, LDH - lactate dehydrogenase, DHAP - dihydroxyacetone phosphate, GA3-P - glyceraldehyde-3-phosphate, 3-PG 3-phosphoglycerate, 2-PG - 2-phosphoglycerate, PEP - phosphoenolpyruvate, GLT1/3 - glucose transporters 1/3, TSC1/TSC2 - Tuberous sclerosis proteins 1 and 2, PDK - P-3-PI-dependent kinase, ADK - adenylate kinase, TK - tyrosine kinase.

Oxley Hughes Ltd (London, UK). Mouse monoclonal antibodies to HIF-1 $\alpha$, mTOR and $\beta$-actin as well as rabbit polyclonal antibodies against phospho-S2448 mTOR and phospho-T2446 mTOR were from Abcam (Cambridge, UK). Antibodies against phospho-T389 p70 S6 kinase 1 (p70 S6K1), total and phospho-S65 eukaryotic initiation factor 4E binding protein 1 (eIF4E-BP1) antibodies were obtained from Cell Signalling Technology (Danvers, MA USA). Goat anti-mouse and goat anti-rabbit fluorescence dye-labelled antibodies were obtained from Li-Cor (Lincoln, Nebraska USA). ELISA-based assay kits for the detection of IL-6, TNF- $\alpha$ and VEGF were purchased from R\&D Systems (Abingdon, UK). All other chemicals were of the highest grade of purity that were commercially available (from either Sigma or Fisher Scientific).

\section{THP-1 human myeloid cells}

THP-1 human leukaemia monocytic macrophages were obtained from the European collection of Cell Cultures (Salisbury, UK). Cells were cultured in RPMI 1640 media supplemented with $10 \%$ foetal calf serum, penicillin (50 IU/ $\mathrm{ml})$ and streptomycin sulfate $(50 \mu \mathrm{g} / \mathrm{ml})$. Cells used in the experiments were from the 5-35th passage.

\section{Primary human AML cells}

Primary human AML mononuclear cells (AMLPB001F, newly diagnosed/untreated) were purchased from AllCells (Alameda, CA, USA) and handled in accordance with manufacturer's instructions. Cells derived from two different patients were used in the experiments.

\section{Primary human leukocytes obtained from healthy donors}

Primary human leukocytes were obtained from buffy coat blood (prepared from healthy donors) purchased from the National Health Blood and Transfusion Service (NHSBT, UK) following ethical approval (REC reference: 12/ WM/0319). Mononuclear-rich leukocytes were obtained by Ficoll-density centrifugation according to the manufacturer's 
protocol. Cell numbers were determined using a haemocytometer and diluted accordingly with HEPES-buffered Tyrode's solution before treatment as indicated.

\section{Primary human basophils}

Primary human basophils were obtained from buffy coats and isolated from the leukocyte-rich fraction obtained by Ficoll density centrifugation as described above. Basophils were then purified by a negative selection procedure to 90-100\% purity (as judged by alcian blue staining) using a commercially available kit, as previously described [28]. Basophils were pre-incubated for $15 \mathrm{~min}$ at $37^{\circ} \mathrm{C}$ in HEPESbuffered Tyrode's solution and then treated as indicated.

\section{Stem cell factor}

Human SCF protein was produced in E.Coli and purified in accordance with published protocols [29].

\section{Western blot analysis}

Expressions of HIF-1 $\alpha$, total and phospho-T389 p70 S6K1, total and phospho-S65 eIF4E-BP1 as well as XOD protein levels were determined by Western blot analysis and compared to $\beta$-actin in order to determine equal protein loading, as previously described [10]. Li-Cor goat secondary antibodies, conjugated with fluorescent dyes, were used according to the manufacturer's protocol in order to visualise the proteins of interest using a Li-Cor Odyssey imaging system. Western blot data were subjected to quantitative analysis using Odyssey software and values were normalised against respective $\beta$-actin bands.

\section{Detection of phospho-S2448 and phospho-T2446 mTOR in cell lysates by ELISA}

Phosphorylation of mTOR was monitored using ELISA assays as recently described [10, 21, 30]. Briefly, the ELISA plates were coated with mouse anti-mTOR antibodies and blocked with $2 \%$ BSA. Cell lysates were then added to the wells and kept at room temperature for at least $2 \mathrm{~h}$ (under constant agitation). After extensive washing with TBST buffer, anti-phospho-S2448 (or antiphospho-T2446) mTOR antibody was added and plates were incubated for at least $2 \mathrm{~h}$ at room temperature with constant agitation. Plates were then washed with TBST buffer and incubated with 1:1000 HRP-labelled goat antirabbit IgG in TBST buffer. After extensive washing with TBST, bound secondary antibodies were then detected by the peroxidase reaction (ortho-phenylenediamine $/ \mathrm{H}_{2} \mathrm{O}_{2}$ ).

\section{HIF-1 $\alpha$ PHD assay}

To detect HIF-1 $\alpha$ PHD activity we employed a peptide-based assay [31]. HIF-1 $\alpha$-free cell lysates were used to avoid the impact of intracellular HIF-1 $\alpha$ hydroxylation. Lysates of non-treated and treated THP1 cells were incubated for one hour in 96-well ELISA plates which were coated with HIF-1 $\alpha$ capture antibodies and blocked with BSA as described previously. Lysates were then subjected PHD assay following this incubation period.

\section{Detection of intracellular ATP, cAMP, AMP, ROS and 2-OG levels, xanthine oxidase activity as well as glycolysis intensity}

ATP was detected using a commercial luminometric kit (Sigma) according to the manufacturer's protocol. AMP and cAMP levels were detected using luminometric assay kits in accordance with manufacturer's protocols. Intracellular ROS levels were also monitored by luminometric assay as previously described [32]. 2-OG levels were analysed using a glutamate dehydrogenase spectrophotometric assay [33]. Xanthine oxidase activity was measured as described before [21]. The intensity of glycolysis was determined based on the ability cell lysate enzymes, used as a multienzyme preparation, to convert glucose into lactate under anaerobic conditions, which was achieved by employing an anaerobic chamber [10].

\section{Detection of IL-6, TNF- $\alpha$ and VEGF release}

Concentrations of these cytokines released into the cell culture media were analysed by ELISA (R\&D Systems assay kit) according to the manufacturer's protocol.

\section{Measurement of histamine release}

Histamine releases were assessed using spectrofluorometic autoanalysis as previously described [34]. Histamine releases were calculated from the histamine contents released into the supernatants as a percentage of total histamine content present in lysed cell pellets.

\section{High performance liquid chromatography}

Caffeine and its metabolites were analysed in urine according to a previously described protocol $[35,36]$ with minor modifications. Healthy subjects were asked to refrain from all caffeine containing beverages and chocolate for 1 day. At 8 a.m. on the test day subjects were asked to consume 2 cups of very strong espresso (approximately $200 \mathrm{mg}$ of caffeine) and 6 hours later urine was collected for analysis.

$10 \mathrm{ml}$ of urine were mixed with $200 \mathrm{mg}$ of ascorbic acid. The $\mathrm{pH}$ was adjusted to 3.5 with $30 \%$ acetic acid. $200 \mu \mathrm{l}$ of urine were mixed with $140 \mathrm{mg}$ of ammonium sulfate, $25 \mu \mathrm{l}$ of internal standard (137 MU) and vortexed at full speed for $1 \mathrm{~min}$. The metabolites were extracted with chloroform:isopropanol (95:5) and centrifuged. The organic phase was evaporated to dryness using nitrogen or Speedvac and the pellet was dissolved in $750 \mu \mathrm{l}$ of diluent 
containing $\mathrm{MeOH}$ : acetic acid : water (20:0.5:979.5 vol:vol:vol) and $5 \mu \mathrm{l}$ of the sample was analysed by Agilent HPLC system (the flow rate was $0.5 \mathrm{ml} / \mathrm{min}$ ) with a UV detector using a gradient elution profile. Caffeine, caffeine metabolites and the internal standard were separated on an Agilent XBD C18 reverse phase column $(1.8 \mu \mathrm{m}, 4.6 \times 50 \mathrm{~mm})$. The solvents used for the elution were mobile phase A containing $\mathrm{MeOH}$ : acetic acid : water (20:0.5:979.5 vol:vol:vol) and mobile phase B (MeOH : acetic acid : water 700:0.5:229.5 vol:vol:vol). The gradient program was $0 \%$ B ( $0 \mathrm{~min}), 100 \%$ ( 0.1 to 15 $\mathrm{min}$ ) and $0 \%$ (15.1 to $18 \mathrm{~min})$. The analytes were detected by UV absorbance at $280 \mathrm{~nm}$. Calibration curves were developed using known amounts of metabolites.

\section{Analysis of total cytochrome $\mathrm{P450}$ and activity of CYP450 1A2}

Total CYP450 was analysed by a classic spectrophotometric method initially proposed by Omura and Sato [37]. CYP450 1A2 activity was analysed based on its ability to oxidise caffeine using NADPH as a donor. Mouse liver homogenates obtained from commercial sources were used as positive control.

\section{Statistical analysis}

Each experiment was performed at least three times and statistical analysis was conducted using a two-tailed Student's $t$ test. Statistical probabilities (p) were expressed as $*$, where $p<0.01$.

\section{ACKNOWLEDGMENTS}

Alexandr Prokhorov was a fellow of the European Academy of Allergy and Clinical Immunology (EAACI). Regretfully, he has tragically died in an accident in recent past. The work was partially supported by the University of Kent Faculty of Sciences Research Fund. We are also grateful to Dr. Simon Stafford (Oxley Hughes Ltd, London, UK) for the gift of ELISA plates and to Ms Irene Wegner (University of Applied Sciences Northwestern Switzerland, Institute of Chemistry and Bioanalytics) for her assistance with HPLC experiments. We are most grateful to Dr. Luca Varani from Institute for Research in Biomedicine, Universita' della Svizzera Italiana (USI) via Vela 6, 6500 Bellinzona, Switzerland for his generous help with SCF purification.

\section{CONFLICTS OF INTEREST}

There is no conflict of interest that the authors should disclose.

\section{REFERENCES}

1. Miners JO, Birkett DJ. The use of caffeine as a metabolic probe for human drug metabolizing enzymes. Gen Pharmacol. 1996; 27:245-249.

2. Stefanovich V. Cyclic 3',5'-adenosine monophosphate phosphodiesterase (cAMP PDE) and cyclic 3',5'-guanosine monophosphate phosphodiesterase (cGMP PDE) in microvessels isolated from bovine cortex. Neurochem Res. 1997; 4:681-687.

3. Spriet LL, MacLean DA, Dyck DJ, Hultman E, Cederblad G, Graham TE. Caffeine ingestion and muscle metabolism during prolonged exercise in humans. Am J Physiol. 1992; 262:E891-898.

4. Donsmark M, Langfort J, Holm C, Ploug T, Galbo H. Contractions activate hormone-sensitive lipase in rat muscle by protein kinase $\mathrm{C}$ and mitogen-activated protein kinase. $\mathrm{J}$ Physiol. 2003; 550:845-854.

5. Krovat BC, Tracy JH, Omiecinski CJ. Fingerprinting of cytochrome P450 and microsomal epoxide hydrolase gene expression in human blood cells. Toxicol Sci. 2000; 55:352-360.

6. Sumbaev VV, Rozanov AY. Effect of caffeine on xanthine oxidase activity. Ukr Biokhim Zh. 1997; 69:196-200.

7. Miwa S, Sugimoto N, Yamamoto N, Shirai T, Nishida H, Hayashi K, Kimura H, Takeuchi A, Igarashi K, Yachie A, Tsuchiya H. Caffeine induces apoptosis of osteosarcoma cells by inhibiting AKT/mTOR/S6K, NF-kappaB and MAPK pathways. Anticancer Res. 2012; 32:3643-3649.

8. Saiki S, Sasazawa Y, Imamichi Y, Kawajiri S, Fujimaki T, Tanida I, Kobayashi H, Sato F, Sato S, Ishikawa K-I, Imoto M, Hattori N. Caffeine induces apoptosis by enhancement of autophagy via PI3K/Akt/mTOR/p70S6K inhibition. Autophagy. 2011; 7:176-187.

9. Xie J, Ponuwei GA, Moore CE, Willars GB, Tee AR, Herbert TP. cAMP inhibits mammalian target of rapamycin complex-1 and -2 (mTORC1 and 2) by promoting complex dissociation and inhibiting mTOR kinase activity. Cell Signal. 2011; 23:1927-1935.

10. Yasinska IM, Gibbs BF, Lall GS, Sumbayev VV. The HIF-1 transcription complex is essential for translational control of myeloid hematopoietic cell function by maintaining mTOR phosphorylation. Cell Mol Life Sci. 2014; 71:699-710.

11. Semenza GL. HIF-1 and tumor progression: pathophysiology and therapeutics. Trends Mol Med. 2002; 8:S62-67.

12. Walmsley SR, Cadwallader KA, Chilvers ER. The role of HIF-1alpha in myeloid cell inflammation. Trends Immunol. 2005; 26:434-439.

13. Natarajan G, Lulic-Botica M, Aranda JV. Clinical pharmacology of caffeine in the newborn. NeoReviews. 2007; 8:e214-e221. 
14. Akira S, Takeda K. Toll-like receptor signalling. Nat Rev Immunol. 2004; 4:499-511.

15. Nolan LL, Kidder GW. Caffeine: its action on purine metabolizing enzymes. Biochem Biophys Res Commun. 1979; 91:253-262.

16. Ferrer I, Costell M, Grisolia S. Lesch-Nyhan syndromelike behavior in rats from caffeine ingestion: changes in HGPRTase activity, urea and some nitrogen metabolism enzymes. FEBS Lett. 1982; 141:275-278.

17. Nicholas SA, Bubnov VV, Yasinska IM, Sumbayev VV. Involvement of xanthine oxidase and hypoxia-inducible factor 1 in Toll-like receptor 7/8-mediated activation of caspase 1 and interleukin-1beta. Cell Mol Life Sci. 2011; 68:151-158.

18. Pollizzi KN, Powell JD. Integrating canonical and metabolic signalling programmes in the regulation of $\mathrm{T}$ cell responses. Nat Rev Immunol. 2014; 14:435-446.

19. Sumbayev VV, Nicholas SA. Hypoxia-inducible factor 1 as one of the "signaling drivers" of Toll-like receptordependent and allergic inflammation. Arch Immunol Ther Exp (Warsz). 2010; 58:287-294.

20. Nicholas SA, Sumbayev VV. The role of redox-dependent mechanisms in the downregulation of ligand-induced Toll-like receptors 7, 8 and 4-mediated HIF-1 alpha prolyl hydroxylation. Immunol Cell Biol. 2010; 88:180-186.

21. Abooali M, Lall GS, Coughlan K, Lall HS, Gibbs BF, Sumbayev VV. Crucial involvement of xanthine oxidase in the intracellular signalling networks associated with human myeloid cell function. Sci Rep. 2014; 4:6307.

22. Frenz AM, Gibbs BF, Pearce FL. The effect of recombinant stem cell factor on human skin and lung mast cells and basophil leukocytes. Inflamm Res. 1997; 46:35-39.

23. Sumbayev VV, Yasinska IM, Oniku AE, Streatfield CL, Gibbs BF. Involvement of hypoxia-inducible factor-1 in the inflammatory responses of human LAD2 mast cells and basophils. PLoS One. 2012; 7:e34259.

24. Sumbayev VV, Nicholas SA, Streatfield CL, Gibbs BF. Involvement of hypoxia-inducible factor-1 HIF(1alpha) in IgE-mediated primary human basophil responses. Eur J Immunol. 2009; 39:3511-3519.

25. Degang Y, Akama T, Hara T, Tanigawa K, Ishido Y, Gidoh M, Makino M, Ishii N, Suzuki K. Clofazimine modulates the expression of lipid metabolism proteins in Mycobacterium leprae-infected macrophages. PLoS Negl Trop Dis. 2012; 6:e1936.

26. Cheng SC, Quintin J, Cramer RA, Shepardson KM, Saeed S, Kumar V, Giamarellos-Bourboulis EJ, Martens JH, Rao NA, Aghajanirefah A, Manjeri GR, Li Y, Ifrim DC, Arts RJ, van der Veer BM, Deen PM, Logie C, O'Neill LA, Willems P, van de Veerdonk FL, van der Meer JW, Ng A, Joosten LA,
Wijmenga C, Stunnenberg HG, Xavier RJ, Netea MG. mTOR- and HIF-1alpha-mediated aerobic glycolysis as metabolic basis for trained immunity. Science. 2014; 345:1250684.

27. Ren H, Teng Y, Tan B, Zhang X, Jiang W, Liu M, Du B, Qian M. Toll-like receptor-triggered calcium mobilization protects mice against bacterial infection through extracellular ATP release. Infect Immun. 2014; 82:5076-5085.

28. Gibbs BF, Papenfuss K, Falcone FH. A rapid two-step procedure for the purification of human peripheral blood basophils to near homogeneity. Clin Exp Allergy. 2008; 38:480-485.

29. Wang C, Liu J, Wang L, Geng X. Solubilization and refolding with simultaneous purification of recombinant human stem cell factor. Appl Biochem Biotechnol. 2008; 144:181-189.

30. Prokhorov A, Gibbs BF, Bardelli M, Ruegg L, Fasler-Kan E, Varani L, Sumbayev VV. The immune receptor Tim-3 mediates activation of PI3 kinase/mTOR and HIF-1 pathways in human myeloid leukaemia cells. Int J Biochem Cell Biol. 2015; 59:11-20.

31. Gibbs BF, Yasinska IM, Oniku AE, Sumbayev VV. Effects of stem cell factor on hypoxia-inducible factor 1 alpha accumulation in human acute myeloid leukaemia and LAD2 mast cells. PLoS One. 2011; 6:e22502.

32. Kapiszewska M, Cierniak A, Elas M, Lankoff A. Lifespan of etoposide-treated human neutrophils is affected by antioxidant ability of quercetin. Toxicol In Vitro. 2007; 21:1020-1030.

33. Kozhukhar AV, Yasinska IM, Sumbayev VV. Nitric oxide inhibits HIF-1alpha protein accumulation under hypoxic conditions: implication of 2-oxoglutarate and iron. Biochimie. 2006; 88:411-418.

34. Shore PA, Burkhalter A, Cohn VH Jr. A method for the fluorometric assay of histamine in tissues. J Pharmacol Exp Ther. 1959; 127:182-186.

35. Butler MA, Lang NP, Young JF, Caporaso NE, Vineis P, Hayes RB, Teitel CH, Massengill JP, Lawsen MF, Kadlubar FF. Determination of CYP1A2 and NAT2 phenotypes in human populations by analysis of caffeine urinary metabolites. Pharmacogenetics. 1992; 2:116-127.

36. Sarkar M, Stabbert R, Kinser RD, Oey J, Rustemeier K, von Holt K, Schepers G, Walk RA, Roethig HJ. CYP1A2 and NAT2 phenotyping and 3-aminobiphenyl and 4-aminobiphenyl hemoglobin adduct levels in smokers and non-smokers. Toxicol Appl Pharmacol. 2006; 213:198-206.

37. Omura T, Sato R. The Carbon Monoxide-Binding Pigment of Liver Microsomes. I. Evidence for Its Hemoprotein Nature. J Biol Chem. 1964; 239:2370-2378. 